\title{
Femoral blood concentrations of flualprazolam in 33 postmortem cases
}

Kriikku, Pirkko

2020-02

Kriikku , P , Rasanen , I , Ojanperä , I , Thelander , G , Kronstrand , R \& Vikingsson , S 2020

, ' Femoral blood concentrations of flualprazolam in 33 postmortem cases ' , Forensic Science International , vol. 307 , 110101 . https://doi.org/10.1016/j.forsciint.2019.110101

http://hdl.handle.net/10138/323513

https://doi.org/10.1016/j.forsciint.2019.110101

cc_by_nc_nd

acceptedVersion

Downloaded from Helda, University of Helsinki institutional repository.

This is an electronic reprint of the original article.

This reprint may differ from the original in pagination and typographic detail.

Please cite the original version. 


\section{Femoral blood concentrations of flualprazolam in 33 postmortem cases}

Pirkko Kriikkua,b, Ilpo Rasanenª, Ilkka Ojanperäb,a, Gunilla Thelanderc, Robert Kronstrandc,d Svante Vikingsson ${ }^{\mathrm{c}, \mathrm{d}}$

a. Forensic Toxicology Unit, Finnish Institute for Health and Welfare, P.O. Box 30, 00271 Helsinki, Finland

b. Department of Forensic Medicine, University of Helsinki, Finland

c. Department of Forensic Genetics and Forensic Toxicology, National Board of Forensic Medicine, Linköping, Sweden

d. Division of Drug Research, Department of Medical and Health Sciences, Linköping University, Sweden

Corresponding author: Pirkko Kriikku (pirkko.kriikku@thl.fi)

\section{Highlights}

- Flualprazolam was frequently detected in fatalities in Sweden and Finland

- Flualprazolam was implicated in the cause of death in $40 \%$ of the studied cases

- Flualprazolam was the only intoxicant found in two (6\%) poisoning cases

- The age in the Finnish cases was significantly lower than in the Swedish cases 


\section{Abstract}

Flualprazolam is a novel designer benzodiazepine, structurally related to alprazolam, flubromazolam and triazolam. In the last couple of years, it has been frequently detected in seizures and in forensic cases in Sweden and Finland. However, there is a lack of published blood concentrations for the drug, which presents difficulties when assessing its relevance for the cause of death.

A quantitative method for the determination of flualprazolam in post-mortem blood was developed and validated, and subsequently used to analyse samples from 33 deaths previously screened as testing positive for flualprazolam in Sweden and Finland.

Most of the cases in the study were accidental deaths (61\%) or suicides (18\%). The median (range) flualprazolam concentration was 18.0 (3.0-68) $\mathrm{ng} / \mathrm{g}$. The majority of the deceased were male (82\%) and the median age was 30 years. The median age in the Swedish cases was significantly higher (35 years) than in the Finnish cases (23 years) $(p<0.05)$. Poly-drug use and particularly the concomitant use of flualprazolam and opioids were very common in the study population. Most of the cases that were positive for flualprazolam were fatal poisonings by a drug $(N=23)$, and in 13 cases, flualprazolam was implicated in the cause of death.

Combining the resources of two countries in which all post-mortem toxicology is centralised provided a more comprehensive insight into the toxicology of flualprazolam. Research on novel psychoactive substances, such as flualprazolam, is required in order to be able to provide scientific evidence on the risks of these new substances for drug administration and potential users. 


\section{Introduction}

The new psychoactive substance flualprazolam is a designer benzodiazepine formally notified by the European Monitoring Centre for Drugs and Drug Addiction (EMCDDA) on behalf of Sweden in February 2018, and it was also identified by German researchers in samples from controlled purchases in late 2017 [1,2].

In Sweden, flualprazolam was first seized by the police in November 2017 and in Finland by customs in February 2018. Since then, flualprazolam has been detected in over 500 seizures (predominantly in Sweden), mainly in the form of tablets.

Flualprazolam is the ortho-fluoro analogue of alprazolam and is also structurally related to triazolam and flubromazolam (as seen in figure 1). Flualprazolam was first described in a patent filed by the Upjohn Company in 1969 [3] where it was shown to have similar potency to triazolam and be more potent than alprazolam in a number of tests on mice models. These results were further explored by Hester et al. [4] by additional tests in mice models. The results indicate that flualprazolam adds to the sedative effect of ethanol and pentobarbital at concentrations similar to those of alprazolam and approximately at an order of magnitude lower than those of diazepam. The high potency is also reported by user communities with Tripsit [5] who reported common doses of 0.2 to $0.5 \mathrm{mg}$ (alprazolam $0.5-1.5 \mathrm{mg}$ ).

The metabolism of flualprazolam was investigated using human liver microsomes by Wilde et al. [1], who reported hydroxylations at either the $\alpha$-position of the triazolo ring or the 4position of the diazepine ring (as shown in figure 1).

Mei et al. [6] developed a liquid chromatography tandem mass spectrometry (LC-MS/MS) method to measure 13 different designer benzodiazepines in post-mortem blood after solid phase extraction. In one sample, $1.9 \mathrm{ng} / \mathrm{mL}$ in femoral blood was reported without case details. To the best of our knowledge this is the only information available on flualprazolam concentrations in blood, limiting the ability to interpret suspected flualprazolam intoxications as well as to identify appropriate limits of quantification for screening and confirmation assays.

Flualprazolam is topical in Sweden and Finland as a substantial number of post-mortem cases testing positive for this drug have been found within a short period of time. The aims of this study were to develop and validate a quantitative method for flualprazolam in blood by using a gas-chromatography negative-chemical-ionization mass spectrometry (GC-NCI-MS) method modified for the purpose from the work Gunnar et al. in 2006 [7], and to use the method to quantify flualprazolam in the post-mortem cases from both Sweden and Finland, relating the results to the case findings.

\section{Material and methods}


Flualprazolam was included in the GC-NCI-MS method for the quantitative screening of benzodiazepine drugs and metabolites. Alprazolam-d5 was used as an internal standard for flualprazolam. Neither flualprazolam nor alprazolam-d5 form silyl derivatives in the sample preparation process.

\section{Chemicals and materials}

Flualprazolam $1.0 \mathrm{mg} / \mathrm{mL}$ in methanol was purchased from Chiron AS, Trondheim, Norway. Diazepam-d5 $1.0 \mathrm{mg} / \mathrm{mL}$, nordiazepam-d5 $1.0 \mathrm{mg} / \mathrm{mL}$, temazepam-d5 $1.0 \mathrm{mg} / \mathrm{mL}$, oxazepamd5 $1.0 \mathrm{mg} / \mathrm{mL}$, clonazepam-d4 $100 \mathrm{ng} / \mathrm{mL}$ and alprazolam-d5 $100 \mathrm{ng} / \mathrm{mL}$ in methanol were from Cerilliant, Round Rock, Texas, USA. $N$-Methyl- $N$-tert-

butyldimethylsilyltrifluoroacetamide (MTBSTFA) with 1\% tert-butyldimethylchlorosilane (TBDMSCl) was from Sigma-Aldrich, Steinheim, Germany.

The extraction solvent contained $0.50 \mathrm{ng} / \mathrm{mL}$ each of diazepam-d5, nordiazepam-d5, temazepam- $\mathrm{d} 5$ and oxazepam- $\mathrm{d} 5$, and $0.10 \mathrm{ng} / \mathrm{mL}$ each of clonazepam- $\mathrm{d} 4$ and alprazolam- $\mathrm{d} 5$ in butyl acetate.

Calibration and validation experiments were carried out using lamb's blood fortified with 1\% sodium fluoride $(\mathrm{NaF})$.

\section{Sample preparation}

The blood sample $(0.5 \mathrm{~g})$ was transferred into a $6 \mathrm{~mL}$ centrifuge tube, $0.5 \mathrm{ml}$ of $0.5 \mathrm{M} \mathrm{Na}_{2} \mathrm{HPO}_{4}$ buffer solution ( $\mathrm{pH}$ ) ) was added, and the tube was mixed for five seconds in a vortex mixer. The extraction solvent $(0.5 \mathrm{~mL})$ was added, and the tube was mixed for 30 seconds in a vortex mixer. After centrifuging ( $5 \mathrm{~min}, 4330 \mathrm{~g}$ ), the organic layer $(50 \mu \mathrm{L})$ was transferred into a conical-bottomed autosampler vial and evaporated to dryness under a gentle steam of nitrogen $\left(85^{\circ} \mathrm{C}, 30-45 \mathrm{~s}\right)$. Butyl acetate $(50 \mu \mathrm{L})$ and MTBSTFA with $1 \%$ TBDMSCl $(10 \mu \mathrm{L})$ were added, and the vial was capped and heated at $85^{\circ} \mathrm{C}$ for 30 minutes.

\section{Gas chromatography-mass spectrometry}

GC-NCI-MS was performed with a 7977A mass selective detector coupled to a 7890B gas chromatograph, equipped with a 7693 injector (Agilent Technologies, Santa Clara, CA, USA) and a ZB-DRUG-1 (15 m x $0.25 \mathrm{~mm}, 0.25 \mu \mathrm{m}$ ) capillary column (Phenomenex, Torrance, CA, USA). GC-NCI-MS was operated with MassHunter software. Gas chromatography (GC) was used in the splitless and constant flow mode using a $1 \mu \mathrm{L}$ injection volume and a column flow rate of $2.5 \mathrm{~mL}$ of helium 5.6 (99.9996\%) per minute. The injector temperature was $250^{\circ} \mathrm{C}$ and the transfer line temperature was $300^{\circ} \mathrm{C}$. The oven temperature was initially held at $160^{\circ} \mathrm{C}$ for $1 \mathrm{~min}$ and then increased by $50^{\circ} \mathrm{C}$ per min to $320^{\circ} \mathrm{C}$, which was then held for $2 \mathrm{~min}$. The NCI mode was used with methane $5.5(99.9995 \%)$ as a reagent gas. The flow controller was set at $40 \%$. The quadrupole and ion source temperatures were $150^{\circ} \mathrm{C}$. GC-NCI-MS analysis was performed by selected ion monitoring (SIM) with dwell time of $10 \mathrm{~ms}$, using the ions $\mathrm{m} / z 326$ and 328 for flualprazolam and $m / z 313$ and 315 for alprazolam-d5. The runtime of the 
analysis was 6.2 minutes, and the retention times for flualprazolam and alprazolam-d5 4.626 min and $4.788 \mathrm{~min}$, respectively.

\section{Validation}

The working range of the method was studied by constructing calibration curves in blood (table 1). Quadratic calibration models were chosen with 1/x weighting (5, 10, 20, 50 and 125 $\mathrm{ng} / \mathrm{g}$ with flualprazolam concentration $\geq 5.0 \mathrm{ng} / \mathrm{g}$ and 2, 3, 4, 5, 10 and $20 \mathrm{ng} / \mathrm{g}$ with flualprazolam concentration $<5.0 \mathrm{ng} / \mathrm{g}$ ). The following correlation coefficient values were obtained: $\mathrm{R}^{2}=0.999932$ for $5-125 \mathrm{ng} / \mathrm{g}$ and $\mathrm{R}^{2}=0.998988$ for $2-20 \mathrm{ng} / \mathrm{g}$.

The acceptance criteria for the working range were 15\% relative standard deviation (RSD) for imprecision and $\pm 15 \%$ for bias using five replicates at each calibration point. The signal-tonoise ratio $(\mathrm{S} / \mathrm{N})$ at the limit of detection (LOD) was $\mathrm{S} / \mathrm{N}>3$.

Table 1. Validation data for flualprazolam in blood

\begin{tabular}{|c|c|c|c|c|c|c|}
\hline & & & & \multicolumn{3}{|c|}{ Between-day accuracy and imprecision* } \\
\hline & $\begin{array}{c}\text { Working } \\
\text { range } \\
\text { (ng/g) }\end{array}$ & $\begin{array}{c}\text { LOD } \\
\text { (ng/g }\end{array}$ & $\begin{array}{c}\text { LOQ } \\
\text { (ng/g }\end{array}$ & $\begin{array}{c}\text { Theoretical } \\
\text { concentration } \\
\text { (ng/g) }\end{array}$ & $\begin{array}{c}\text { Mean } \\
\text { concentration } \\
\text { found (ng/g) }\end{array}$ & $\begin{array}{c}\text { Imprecisio } \\
\mathrm{n} \\
\text { (RSD \%) }\end{array}$ \\
\hline Flualprazolam & $2-20$ & 1 & 2 & 10 & 10.2 & 4.1 \\
& $5-125$ & 1 & 5 & 40 & 39.0 & 3.0 \\
\hline
\end{tabular}

$* N=14$ during a four-week period with calibration model $5-125 \mathrm{ng} / \mathrm{g}$

\section{Post-mortem cases}

The subjects were autopsied in Sweden or Finland in connection with medico-legal cause-ofdeath investigations. Femoral venous blood was collected at autopsy in plastic tubes with $\approx 1 \% \mathrm{NaF}$ and stored at $+4^{\circ} \mathrm{C}$. The study included all cases that were previously proven to be positive for flualprazolam by following standard qualitative drug screening procedures for blood or urine samples during the period from June 2018 to July 2019 in Finland and from February 2018 to January 2019 in Sweden.

The regional ethics committee in Linköping approved the inclusion of the Swedish cases (2018-186/31). According to the Finnish guidelines, no ethics approval was necessary for the Finnish part of the study.

\section{Statistical analysis}

All statistical analyses were carried out using IBM SPSS software (version 25). As the frequency distributions of the blood concentrations and the age of the deceased were skewed, medians were used to characterise the data. The analysis was performed using the MannWhitney $U$ test for independent samples. A $p$ value $<0.05$ was regarded as statistically significant.

\section{Results}


The post-mortem cases that tested positive for flualprazolam in the initial drug screening were analysed using the developed GC-NCI-MS method. The limit of quantification was exceeded by 23 samples from Sweden and 10 from Finland. The flualprazolam blood concentration in each of the cases, the cause and manner of death, and the other relevant findings are given in table 2.

The median (range) concentration in all of the studied cases was 18.0 (3.0-68) ng/g. The median flualprazolam concentration was somewhat lower in the Swedish cases $(17.0 \mathrm{ng} / \mathrm{g})$ than in the Finnish cases $(22.5 \mathrm{ng} / \mathrm{g})$, but the difference was not statistically significant $(p>$ $0.05)$. The median concentration in cases where flualprazolam was implicated in a fatal poisoning was $19.0 \mathrm{ng} / \mathrm{g}$, which is not significantly different from that in the whole study population $(p>0.05)$.

The median (range) age of the deceased was 30 (16-70) years. The median age in the Swedish cases was significantly higher (35 years) than in the Finnish cases (23 years) ( $p<$ $0.05)$. The median age in fatal flualprazolam poisonings $(n=13)$ was 28 years.

Of the deceased that tested positive for flualprazolam, 27 (82\%) were male and $6(18 \%)$ were female. The median age of women (25 years) was lower than that of males (31 years), but the difference was not statistically significant $(p>0.05)$.

In $23(70 \%)$ of the cases, the cause of death was fatal poisoning by a substance and in 13 cases (40\%) flualprazolam was one of the substances implicated in the fatal poisoning. Cases testing positive for flualprazolam were determined to be fatal poisonings more often in Finland than in Sweden (80\% in Finland vs 35\% in Sweden), and the drug was also implicated more often in Finland (50\% in Finland vs 35\% in Sweden). In two poisoning cases, flualprazolam was the only intoxicant reported in the cause of death. In these cases, the concentration of flualprazolam was 19 and $21 \mathrm{ng} / \mathrm{g}$, respectively. One of the cases $(19 \mathrm{ng} / \mathrm{g})$ was stated to be an accident. Both cases were from Sweden. In the poly-drug poisoning cases, opioids, alcohol, pregabalin, and anti-depressants were the drugs most commonly implicated along with flualprazolam.

The most common manner of death in the cases testing positive for flualprazolam was death by accident $(n=19,61 \%)$, followed by suicide $(n=6,18 \%)$, natural death $(n=4,12 \%)$ and an undetermined manner of death $(n=3,9 \%)$. In one case the manner of death was not reported. Three of the suicides were fatal poisonings and three were violent suicides.

Buprenorphine was the most common other finding in cases testing positive for flualprazolam $(n=10)$, followed by medicinal opioids other than buprenorphine $(n=5)$, alcohol $(n=5)$, pregabalin/gabapentin $(n=5)$ and illegal drugs, such as amphetamine or heroin/morphine $(n=5)$. 


\section{Discussion}

We present here the results of a bilateral co-operation project between Sweden and Finland concerning post-mortem toxicology related to flualprazolam. Autopsy cases that were initially positive in the standard qualitative drug screening procedures of the laboratories were subjected to quantitative analysis of the flualprazolam with a validated method in order to produce reference data for future consideration in flualprazolam-positive cases.

The study period was approximately one year (within 2018-2019) in each country, although the exact time differed slightly between the countries. Sweden presented a larger number of cases but the number of flualprazolam poisonings was closer (8 in Sweden, 5 in Finland).

Since there are no previous data on flualprazolam concentrations in clinical or post-mortem cases available, we compared the concentrations in our study to those reported for alprazolam and flubromazolam - two structural relatives of flualprazolam with generally low reported reference concentrations. The concentrations of flualprazolam in our study material (median $18.0 \mathrm{ng} / \mathrm{g}$ ) were quite low when compared to the post-mortem concentrations of alprazolam in compilations available in the scientific literature, which is well in line with the initial information provided by the pharma industry in the 1970s about flualprazolam being more potent than alprazolam $[3,4]$. The scientific literature reports median alprazolam concentrations of $24 \mathrm{ng} / \mathrm{g}(n=12)$ [8] or $50 \mathrm{ng} / \mathrm{g}(n=51)$ [9] when the drug was considered unrelated to the cause of death, $16 \mathrm{ng} / \mathrm{g}(n=67)$ [9] in fatal poisonings caused by alprazolam in combination with other drugs and $33 \mathrm{ng} / \mathrm{mL}(n=2234)$ [10] when all causes of death were taken into account. The post-mortem concentrations reported for flubromazolam in femoral blood in two fatal methadone intoxication cases were lower than the median flualprazolam concentration in our cases -8.0 and $4.4 \mathrm{ng} / \mathrm{g}$ [11]. In a third case, flubromazolam concentration in heart blood was $40 \mathrm{ng} / \mathrm{mL}$ (cause of death not reported) [6]. However, the number of reported flubromazolam found in the literature is too low for meaningful comparison.

The high potency is especially problematic in cases where flualprazolam is sold in fake alprazolam products, as has been reported by drug-checking services [12]. Adverse effects may occur if flualprazolam is mistaken for alprazolam and abused in similar doses.

The deceased testing positive for flualprazolam in Finland were all below 40 years whereas in the Swedish material, eight cases were over 40 years and the oldest as much as 70 years.

Except for the one individual aged 70 years, all the suicide victims in our material were 30 years or younger (median: 23 years). Of the women in our study, 50\% had committed suicide whereas the percentage for men was $11 \%$, which is well in line with previous research suggesting that women with substance abuse problems are more susceptible to committing suicide than men with similar problems [13]. 
Only in two cases was flualprazolam the only drug detected and implicated in the cause of death. The concentrations in these cases (19 and $21 \mathrm{ng} / \mathrm{g}$ ) were close to the median concentration of all the cases. In some cases with high flualprazolam concentrations in our material, the drug was not implicated even when the cause of death was fatal drug poisoning. It can be speculated whether in these cases the potency of the drug was sufficiently acknowledged by the forensic pathologist who determined the cause of death. This is, understandably, a common situation with new drugs that lack post-mortem reference values.

\section{Conclusion}

Both in Sweden and Finland, a considerable number of post-mortem cases were found to test positive for the previously quite unfamiliar benzodiazepine flualprazolam. The lack of previous data on the drug concentrations and toxicity presented a challenge when the relevance of the drug needed to be assessed in case work. Interestingly, differences existed between the two countries in terms of flualprazolam blood concentrations and particularly in the age of the deceased. These findings emphasise the necessity of collecting data from multiple areas in order to obtain a consistent toxicology profile for a new illicit drug. 
Table 2. Details of the cases that tested positive for flualprazolam in Sweden and Finland

\begin{tabular}{|c|c|c|c|c|}
\hline \multicolumn{5}{|c|}{ SWEDEN } \\
\hline Sample & $\begin{array}{l}\text { Flualprazolam } \\
\mathrm{ng} / \mathrm{g}\end{array}$ & Cause of death & $\begin{array}{l}\text { Manner of } \\
\text { death }\end{array}$ & $\begin{array}{l}\text { Other relevant findings ( } \mu \mathrm{g} / \mathrm{g} \text { in femoral } \\
\text { blood, unless stated otherwise) }\end{array}$ \\
\hline S1 & 4.2 & $\begin{array}{l}\text { Fatal poisoning by flualprazolam, } \\
\text { venlafaxine and pregabalin }\end{array}$ & Accident & $\begin{array}{l}\text { Venlafaxine (1.3), 0-desmethyl venlafaxine } \\
(0.45) \text {, pregabalin (16) }\end{array}$ \\
\hline S2 & 18 & $\begin{array}{l}\text { Fatal poisoning by methadone } \\
\text { and flualprazolam }\end{array}$ & Accident & Methadone $(0.15)$ \\
\hline S3 & 9.7 & Fatal poisoning by alimemazine & Accident & $\begin{array}{l}\text { Alimemazine (5.0), desmethyl alimemazine } \\
\text { (1.3) }\end{array}$ \\
\hline S4 & 17 & $\begin{array}{l}\text { Fatal poisoning by } \\
\text { buprenorphine, flualprazolam } \\
\text { and ethanol }\end{array}$ & Accident & $\begin{array}{l}\text { Ethanol (0.67 \%o, in urine: } 1.33 \% \text { \%), } \\
\text { buprenorphine }(2.8 \mathrm{ng} / \mathrm{g}, 0.09 \mu \mathrm{g} / \mathrm{ml} \text { urine })\end{array}$ \\
\hline S5 & 33 & $\begin{array}{l}\text { Ischemic cardiomyopathy caused } \\
\text { by flualprazolam and N-ethyl-3- } \\
\text { fluoroamphetamine intake }\end{array}$ & Accident & $\begin{array}{l}\text { N-ethyl-3-fluoroamphetamine (present), 3- } \\
\text { fluoroamphetamine (present) }\end{array}$ \\
\hline S6 & 28 & $\begin{array}{l}\text { Fatal poisoning by flualprazolam, } \\
\text { mirtazapine and venlafaxine }\end{array}$ & Suicide & $\begin{array}{l}\text { Mirtazapine }(0.20) \text {, desmethyl mirtazapine } \\
(0.10) \text {, venlafaxine }(0.52), 0 \text {-desmethyl } \\
\text { venlafaxine }(0.83)\end{array}$ \\
\hline S7 & 19 & Fatal poisoning by flualprazolam & Accident & - \\
\hline S8 & 20 & $\begin{array}{l}\text { Fatal poisoning by carbon } \\
\text { monoxide }\end{array}$ & Suicide & $\mathrm{COHb}(76 \%)$ \\
\hline S9 & 23 & Bronchopneumonia & Natural & - \\
\hline S10 & 3 & $\begin{array}{l}\text { Brain injury due to trauma from } \\
\text { falling }\end{array}$ & Unclear & - \\
\hline S11 & 5 & Coronary arteriosclerosis & Natural & - \\
\hline S12 & 45 & $\begin{array}{l}\text { Fatal poisoning by heroin } \\
\text { together with buprenorphine and } \\
\text { pregabalin }\end{array}$ & Accident & $\begin{array}{l}\text { Morphine (0.34), 6-monoacetyl morphine } \\
(0.006) \text {, codein }(0.03) \text {, buprenorphine }(2.6 \\
\text { ng/g, } 0.19 \mu \mathrm{g} / \mathrm{ml} \text { urine), norbuprenorphine } \\
(3.9 \mathrm{ng} / \mathrm{g}, 0.09 \mu \mathrm{g} / \mathrm{ml} \text { urine), pregabalin }(21)\end{array}$ \\
\hline S13 & 7.8 & Drug -related death & $\begin{array}{l}\text { Not } \\
\text { reported }\end{array}$ & $\begin{array}{l}\text { Amphetamine (1.7), MDMA (1.7), MDA } \\
(0.08) \text {, oxycodone }(0.1), \text { morphine }(0.04)\end{array}$ \\
\hline
\end{tabular}




\begin{tabular}{|c|c|c|c|c|}
\hline S14 & 20 & Fatal poisoning by buprenorphine & Accident & Buprenorphine $(0.8 \mathrm{ng} / \mathrm{g}, 0.09 \mu \mathrm{g} / \mathrm{ml}$ urine $)$ \\
\hline S15 & 16 & Bronchopneumonia & Natural & - \\
\hline S16 & 14 & $\begin{array}{l}\text { Fatal poisoning by loperamide } \\
\text { and flualprazolam }\end{array}$ & Accident & Loperamide (0.06) \\
\hline S17 & 7.6 & Fatal poisoning by tramadol & Unclear & Tramadol (8.5), 0-desmethyl tramadol (0.43) \\
\hline S18 & 13 & Fatal poisoning by loperamide & Accident & Loperamide (0.17) \\
\hline S19 & 21 & Fatal poisoning by flualprazolam & Unclear & - \\
\hline S20 & 20 & Myocardial infarction & Natural & - \\
\hline S21 & 11 & $\begin{array}{l}\text { Fatal poisoning by buprenorphine } \\
\text { and flualprazolam }\end{array}$ & Accident & $\begin{array}{l}\text { Buprenorphine }(0.9 \mathrm{ng} / \mathrm{g}, 0.04 \mu \mathrm{g} / \mathrm{ml} \text { urine }) \text {, } \\
\text { norbuprenorphine }(0.2 \mathrm{ng} / \mathrm{g})\end{array}$ \\
\hline S22 & 36 & $\begin{array}{l}\text { Fatal poisoning by buprenorphine } \\
\text { and alimemazine }\end{array}$ & Accident & $\begin{array}{l}\text { Buprenorphine }(9.0 \mathrm{ng} / \mathrm{g}, 0.23 \mu \mathrm{g} / \mathrm{ml} \text { urine }) \text {, } \\
\text { norbuprenorphine }(31 \mathrm{ng} / \mathrm{g},>1 \mu \mathrm{g} / \mathrm{ml} \\
\text { urine), alimemazine }(1.9) \text {, desmethyl } \\
\text { alimemazine (1.8) }\end{array}$ \\
\hline S23 & 5.8 & $\begin{array}{l}\text { Brain injury due to trauma from } \\
\text { falling }\end{array}$ & Suicide & - \\
\hline \multicolumn{5}{|c|}{ FINLAND } \\
\hline Sample & $\begin{array}{l}\text { Flualprazolam } \\
\text { ng/g }\end{array}$ & Cause of death & $\begin{array}{l}\text { Manner of } \\
\text { death }\end{array}$ & \\
\hline F1 & 68 & $\begin{array}{l}\text { Fatal poisoning by flualprazolam, } \\
\text { buprenorphine and alcohol }\end{array}$ & Suicide & $\begin{array}{l}\text { Ethanol (0.40 \%o), buprenorphine }(0.94 \mathrm{ng} / \mathrm{g} \text {, } \\
17 \mathrm{ng} / \mathrm{g} \text { urine }) \text {, norbuprenorphine }(0.83 \\
\mathrm{ng} / \mathrm{g}, 15 \mathrm{ng} / \mathrm{g} \text { urine })\end{array}$ \\
\hline $\mathrm{F} 2$ & 6.6 & $\begin{array}{l}\text { Fatal poisoning by tramadol and } \\
\text { pregabalin }\end{array}$ & Accident & $\begin{array}{l}\text { Tramadol (4), 0-desmethyl tramadol (0.56), } \\
\text { pregabalin (6.5) }\end{array}$ \\
\hline F3 & 24 & Fatal poisoning by amphetamine & Accident & Amphetamine (0.80) \\
\hline $\mathrm{F} 4$ & 36 & $\begin{array}{l}\text { Fatal poisoning by } \\
\text { buprenorphine, flualprazolam } \\
\text { and pregabalin }\end{array}$ & Accident & $\begin{array}{l}\text { Buprenorphine (120 ng/g urine), } \\
\text { norbuprenorphine ( } 7.4 \mathrm{ng} / \mathrm{g} \text { urine), } \\
\text { pregabalin } 1.7\end{array}$ \\
\hline F5 & 21 & Hanging & Suicide & - \\
\hline F6 & 8.6 & Crushing injuries & Suicide & - \\
\hline F7 & 30 & $\begin{array}{l}\text { Fatal poisoning by } \\
\text { buprenorphine, flualprazolam, } \\
\text { alcohol and amphetamines }\end{array}$ & Accident & $\begin{array}{l}\text { Ethanol }(0.68 \% 0), 3 \text {-fluoroamphetamine } \\
(0.01) \text {, amphetamine }(1.0) \text {, } \\
\text { methamphetamine }(0.19) \text {, buprenorphine }\end{array}$ \\
\hline
\end{tabular}




\begin{tabular}{|c|c|c|c|c|}
\hline & & & & $\begin{array}{l}(1.1 \mathrm{ng} / \mathrm{g}, 200 \mathrm{ng} / \mathrm{g} \text { urine }) \text {, } \\
\text { norbuprenorphine }(0.66 \mathrm{ng} / \mathrm{g},>200 \mathrm{ng} / \mathrm{g} \\
\text { urine) }\end{array}$ \\
\hline F8 & 32 & $\begin{array}{l}\text { Fatal poisoning by } \\
\text { buprenorphine, flualprazolam } \\
\text { and gabapentin }\end{array}$ & Accident & $\begin{array}{l}\text { Buprenorphine }(8.9 \mathrm{ng} / \mathrm{g},>200 \mathrm{ng} / \mathrm{g} \text { urine }) \\
\text { norbuprenorphine }(6.8 \mathrm{ng} / \mathrm{g}, 200 \mathrm{ng} / \mathrm{g} \\
\text { urine), gabapentin }(5.6)\end{array}$ \\
\hline F9 & 11 & $\begin{array}{l}\text { Fatal poisoning by } \\
\text { buprenorphine, clonazepam and } \\
\text { THC }\end{array}$ & Accident & $\begin{array}{l}\text { Buprenorphine (0.51 ng/g, } 110 \mathrm{ng} / \mathrm{g} \text { urine), } \\
\text { norbupruprenorphine }(14 \mathrm{ng} / \mathrm{g} \text { urine }), 7- \\
\text { aminoclonazepam }(0.040)\end{array}$ \\
\hline F10 & 13 & $\begin{array}{l}\text { Fatal poisoning by flualprazolam } \\
\text { and alcohol }\end{array}$ & Accident & Ethanol $(1.9 \%$ \%) \\
\hline
\end{tabular}




\section{References}

1. M. Wilde, M. Sommer, V. Auwärter, Identification and characterization of the new designer benzodiazepines bromazolam, flualprazolam and fluclotizolam. Poster at TIAFT conference in Ghent 2018.

2. B. Moosmann, V. Auwärter, Designer benzodiazepines: another class of new psychoactive substances, in: H. H. Maurer, S. D. Brandt (Eds.) Handbook of Experimental Pharmacology, New Psychoactive Substances, Springer, Cham, 2018, pp. 383-410.

3. J. B. Hester Jr, U.S. Patent No. 3,987,052. Washington, DC: U.S. Patent and Trademark Office, 1976.

4. J. B. Hester Jr, A. D. Rudzik, B. V. Kamdar, 6-Phenyl-4H-s-triazolo [4, 3-a][1, 4] benzodiazepines which have central nervous system depressant activity, J. Med. Chem. 14 (1971) 1078-1081.

5. https://chat.tripsit.me/ (accessed 11 September 2019)

6. V. Mei, M. Concheiro, J. Pardi, G. Cooper, Validation of an LC-MS/MS Method for the Quantification of 13 Designer Benzodiazepines in Blood, J. Anal. Toxicol. (2019) epublished ahead of print.

7. T. Gunnar, K. Ariniemi, P. Lillsunde, Fast gas chromatography-negative-ion chemical ionization mass spectrometry with microscale volume sample preparation for the determination of benzodiazepines and alpha-hydroxy metabolites, zaleplon and zopiclone in whole blood, J. Mass Spectrom. 41 (2006) 741-754.

8. L. Skov, K. M. D. Holm, S. S. Johansen, K. Linnet, Postmortem brain and blood reference concentrations of alprazolam, bromazepam, chlordiazepoxide, diazepam, and their metabolites and a review of the literature, J. Anal. Toxicol. 40 (2016) 529-536.

9. A. K. Jönsson, C. Söderberg, K. A. Espnes, J. Ahlner, A. Eriksson, M. Reis, H. Druid, Sedative and hypnotic drugs-fatal and non-fatal reference blood concentrations, Forensic Sci. Int. 236 (2014) 138-145.

10. R. A. Ketola, I. Ojanperä, Summary statistics for drug concentrations in post-mortem femoral blood representing all causes of death. Drug Test. Anal. 11 (2019) 1326-1337.

11. C. Noble, M. Mardal, N. Bjerre Holm, S. Stybe Johansen, K. Linnet, In vitro studies on flubromazolam metabolism and detection of its metabolites in authentic forensic samples, Drug Test. Anal. 9 (2017) 1182-1191.

12. https://energycontrol-international.org/alert-update-on-adulterated-samples-ofalprazolam/ (accessed 11 September) 
13. A. S. Landheim, K. Bakken, P. Vaglum, What characterizes substance abusers who commit suicide attempts? Factors related to Axis I disorders and patterns of substance use disorders. Eur. Addict. Res. 12 (2006) 102-108. 